\title{
Microparticles bearing encephalitogenic peptides induce T-cell tolerance and ameliorate experimental autoimmune encephalomyelitis
}

\author{
Daniel R Getts ${ }^{1,2,7}$, Aaron J Martin ${ }^{1,2,7}$, Derrick P McCarthy ${ }^{1,2}$, Rachael L Terry ${ }^{3}$, Zoe N \\ Hunter $^{1,2}$, Woon Teck Yap ${ }^{4}$, Meghann Teague Getts ${ }^{1,2}$, Michael Pleiss ${ }^{5}$, Xunrong Luo ${ }^{2,6}$, \\ Nicholas JC King ${ }^{3}$, Lonnie D Shea ${ }^{4}$, and Stephen D Miller ${ }^{1,2}$ \\ ${ }^{1}$ Department of Microbiology-Immunology, Feinberg School of Medicine, Northwestern University, \\ Chicago, Illinois, USA \\ ${ }^{2}$ Interdepartmental Immunobiology Center, Feinberg School of Medicine, Northwestern \\ University, Chicago, Illinois, USA \\ ${ }^{3}$ The Discipline of Pathology, School of Medical Sciences, Bosch Institute, The University of \\ Sydney, Sydney, New South Wales, Australia \\ ${ }^{4}$ Department of Chemical and Biological Engineering, Northwestern University, Evanston, Illinois, \\ USA \\ ${ }^{5}$ Myelin Repair Foundation, Saratoga, California, USA \\ ${ }^{6}$ Department of Medicine, Feinberg School of Medicine, Northwestern University, Chicago, \\ Illinois, USA
}

\begin{abstract}
Aberrant T-cell activation underlies many autoimmune disorders, yet most attempts to induce Tcell tolerance have failed. Building on previous strategies for tolerance induction that exploited natural mechanisms for clearing apoptotic debris, we show that antigen-decorated microparticles (500-nm diameter) induce long-term T-cell tolerance in mice with relapsing experimental autoimmune encephalomyelitis. Specifically, intravenous infusion of either polystyrene or biodegradable poly(lactide-co-glycolide) microparticles bearing encephalitogenic peptides prevents the onset and modifies the course of the disease. These beneficial effects require microparticle uptake by marginal zone macrophages expressing the scavenger receptor MARCO and are mediated in part by the activity of regulatory T cells, abortive T-cell activation and T-cell anergy. Together these data highlight the potential for using microparticles to target natural apoptotic clearance pathways to inactivate pathogenic $\mathrm{T}$ cells and halt the disease process in autoimmunity.
\end{abstract}

(C) 2012 Nature America, Inc. All rights reserved.

Correspondence should be addressed to S.D.M. (s-d-miller@ northwestern.edu), N.J.C.K. (nickk@ pathology.usyd.edu.au) or L.D.S. (1shea@northwestern.edu).

7 These authors contributed equally to this work.

Note: Supplementary information is available in the online version of the paper.

COMPETING FINANCIAL INTERESTS

The authors declare no competing financial interests.

AUTHOR CONTRIBUTIONS

D.R.G. and A.J.M. designed and performed the majority of the experiments, interpreted results and assisted with manuscript preparation. D.P.M., R.L.T., Z.N.H., W.T.Y. and M.T.G. performed and/or assisted with several experiments. X.L. provided reagents and advice. S.D.M. provided intellectual input, secured the funding and guided experimental design and the preparation of the manuscript with major input from M.P., N.J.C.K. and L.D.S. 
Autoimmune diseases, such as multiple sclerosis, psoriasis, rheumatoid arthritis and type 1 diabetes, are the third ranked cause of human morbidity and mortality in the United States ${ }^{1}$. In these disorders, a failure in immune regulation results in T cell-mediated destruction of self tissues. The pathologic role of $\mathrm{T}$ cells in driving autoimmune diseases has resulted in numerous therapies aimed at inactivating $\mathrm{T}$ cells. The induction of long-term, durable antigen-specific T-cell tolerance is the ideal therapy, but published 'tolerance-inducing' strategies such as $\mathrm{T}$ cell epitope-specific peptides, $\mathrm{T}$ cell-specific antibodies or costimulation blockade ${ }^{2-4}$ have not faired well clinically ${ }^{5-8}$. Each failure was caused by issues associated specifically with the particular target and agent; however, many also involved concerns about safety and marginal efficacy. For example, cytokine release syndrome has been a common issue with the use of monoclonal antibody-based treatments, whereas soluble peptide infusion has induced anaphylactic responses in mouse models ${ }^{9}$.

We previously reported that intravenous administration of soluble peptides crosslinked to syngeneic splenic leukocytes using ethylene carbodiimide (ECDI) safely and efficiently induces antigen-specific immune tolerance, is effective in the prevention and treatment of $\mathrm{T}$ helper type $1\left(\mathrm{~T}_{\mathrm{H}} 1\right)$ cell- and/or $\mathrm{T}_{\mathrm{H}} 17$ cell-mediated autoimmune diseases and overcomes many of the drawbacks of the failed trials involving monoclonal antibodies and soluble peptides ${ }^{10-12}$. This strategy has recently been proven safe in a phase 1 clinical trial in patients with multiple sclerosis (S.D.M., unpublished data). However, the challenge of isolating isologous leukocytes and peptide coupling under good manufacturing practices (GMP) may inhibit clinical application of this therapy. The mechanism underpinning the beneficial effect of this strategy involves the delivery of an antigen in the context of apoptotic carrier cells ${ }^{11,12}$. Therefore, we sought to achieve similar results using inert microparticles (500-nm diameter) instead of apoptotic cells. Microparticles do not have the stability, manufacturing, storage and other issues that complicate clinical translation of apoptotic cell-based therapies. A number of microparticle-based approaches designed to delay the release of small-molecule therapeutics have recently been approved by the US Food and Drug Administration ${ }^{13}$. Microparticles have also been used as adjuvants ${ }^{14}$.

Here we show that microparticles coupled to encephalitogenic myelin epitopes prevent and treat the clinical symptoms of experimental autoimmune encephalomyelitis (EAE), a mouse model of multiple sclerosis. This treatment reduces inflammatory cell infiltration into and damage of the central nervous system (CNS). The beneficial effect of the microparticles requires the scavenger receptor MARCO, as mice deficient in MARCO are resistant to tolerance induced by antigen-linked microparticles but not by soluble peptide or antigencoupled apoptotic cells. Furthermore, tolerance induced by peptide-coupled microparticles depends on both the induction of T-cell anergy and the activity of regulatory $\mathrm{T}\left(\mathrm{T}_{\text {reg }}\right)$ cells. Collectively, this work demonstrates that antigen-linked micro-particles might represent an alternative way to treat $\mathrm{T}$ cell-based autoimmune disorders by inducing $\mathrm{T}$-cell tolerance.

\section{RESULTS}

\section{Antigen-linked polystyrene beads prevent and treat EAE}

The removal of apoptotic debris normally occurs without immune activation ${ }^{15}$. We have previously shown that intravenously (i.v.) administered apoptotic cells localize to the splenic marginal zone, where they mediate changes in scavenger receptor expression and upregulate interleukin-10 (IL-10) production ${ }^{12}$. Antigen-coupled apoptotic cell tolerance requires upregulation IL-10 production by macrophages, induction of Treg cells and co-inhibition of T cells through the CTLA-4 and PD- 1 pathways ${ }^{12,16-18}$. It is therefore crucial to identify a particle carrier that localizes to similar areas of the spleen and does not trigger immune activation pathways. We postulated that peptide-coupled syngeneic splenic leukocytes 
(antigen-splenocyte, Ag-SP) could be replaced by inert microparticles covalently linked with antigen.

We thus tested the ability of carboxylated 500-nm polystyrene beads (PSB) coupled with the immunodominant myelin proteolipid protein $\mathrm{PLP}_{139-151}$ epitope ( $\mathrm{PLP}_{139-151}$-PSB) to induce tolerance for the prevention and treatment of relapsing-remitting EAE (R-EAE). In this mouse model of relapsing-remitting multiple sclerosis, SJL/J mice are injected with $\mathrm{PLP}_{139-151}$ in adjuvant initiating an autoreactive PLP-specific CD4 ${ }^{+} \mathrm{T}$-cell response leading to the primary disease phase characterized by hindlimb paralysis. Mice then spontaneously remit from acute disease, although the tissue damage resulting from the primary response promotes the activation of T cells targeting a second PLP epitope, PLP $178-191$. This phenomenon is termed 'epitope spreading' and subsequently causes a second round (relapse) of hindlimb paralysis. In the same way, if mice are initially injected with PLP $178-191$ (the subdominant epitope), PLP $_{139-151}$ will function as the spread epitope. Injection of

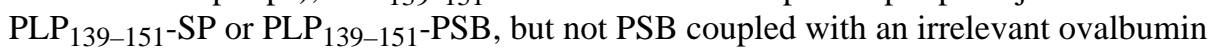

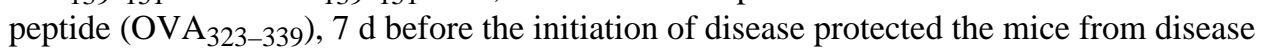
(Fig. 1a). Treatment with PLP $139-151^{-P S B}$ at the first sign of symptoms (11 d after induction of disease) also prevented disease initiation in the vast majority of mice (Fig. 1b), and this effect lasted for at least $66 \mathrm{~d}$ (Fig. 1c). Although injection of PLP $139-151$-PSB $7 \mathrm{~d}$ before injection of PLP $178-191$ mixed with complete Freund's adjuvant (CFA) did not prevent acute disease, indicating the antigen specificity of the tolerance, it did prevent relapse (Fig. 1d), indicating that this treatment could prevent epitope spreading.

Treatment with PLP peptide-coupled PSB affected T-cell function. For example, we showed inactivation of myelin-specific $\mathrm{CD} 4^{+} \mathrm{T}$ cells by a lack of delayed-type hypersensitivity (DTH) responses, an in vivo measure of $\mathrm{CD}^{+} \mathrm{T}$-cell function, to both the immunizing $\left(\mathrm{PLP}_{139-151}\right)$ and spread epitope $\left(\mathrm{PLP}_{178-191}\right)$ (Fig. 1e, f)10. Treatment with $\mathrm{PLP}_{139-151^{-}}$ PSB also reduced leukocyte $\left(\mathrm{CD}^{4} 5^{+}\right)$and $\mathrm{CD} 4^{+}$T-cell infiltration of the CNS (Fig. 1g, $\mathrm{h}$ ). In addition, similarly to Ag-SP, Ag-PSB did not result in anaphylactic responses in mice with established disease unlike administration of soluble peptides ${ }^{9}$.

We next addressed the importance of covalent peptide linkage, microparticle size and route of administration. Covalent linkage with ECDI was essential, as PSB incubated with PLP $_{139-151}$ in the absence of ECDI had no impact on disease (Fig. 1i). Normalizing for peptide mass (with each dose containing $20 \mu \mathrm{g}$ of peptide), we coupled PLP $\mathrm{P}_{139-151}$ to particles with varying diameters (Fig. 1j). Although 4.5- $\mu \mathrm{m}$ and $1.75-\mu \mathrm{m}$ diameter particles provided some disease modification, optimal disease protection was conferred by treatment with the standard 500-nm PLP $139-151$-PSB, whereas 100-nm PLP $139-151$-PSB prevented relapse but did not confer any protection during acute disease. In addition, similarly to Ag$\mathrm{SP}^{12}$, intravenous but not subcutaneous administration of PLP $139-151$-PSB protected against $\mathrm{PLP}_{139-151}$-initiated disease (Fig. 1k) and prevented in vitro antigen-specific $\mathrm{T}$ cell-recall responses (Fig. 11).

\section{MARCO mediates tolerance induction}

The influence of microparticle size and administration route suggests that interactions with phagocytic cells in the splenic marginal zone may be crucial for microparticle-induced tolerance. We previously showed that the infusion of apoptotic debris upregulates the expression of select scavenger receptors, such as MARCO, in the spleen ${ }^{12}$. Scavenger receptors comprise a set of structurally diverse proteins, expressed predominately by phagocytes, that are important in the clearance of modified lipid particles and polyanionic ligands of both host and pathogen origin ${ }^{19}$. MARCO contributes to the uptake and clearance of particulate debris ${ }^{20,21}$. We found that fluorescein isothiocyanate (FITC)-labeled PLP $_{139-151}$-PSB administered i.v. localized with $\mathrm{MARCO}^{+}$cells in the splenic marginal 
zone, presumably the highly phagocytic marginal zone macrophages (MZMs) (Fig. 2$)^{22}$. The cells containing FITC-labeled PLP ${ }_{139-151}$-PSB also expressed SIGN-R1, the murine homolog of DC-SIGN (Fig. 2b, e) that is expressed by MZMs with professional antigenpresenting capabilities ${ }^{23,24}$, but they did not express SIGLEC-1, a marker that defines metallophilic macrophages (Fig. 2c, f). Overall, the data indicate that PLP $139-151$-PSB administered i.v. localizes to MARCO+ MZMs.

We confirmed the importance of MARCO in peptide-coupled particle tolerance using MARCO-deficient $\left(\mathrm{MarCo}^{-1-}\right) \mathrm{BALB} / \mathrm{c}$ mice. Specifically, OVA $323-339-\mathrm{PSB}$ administered i.v. resulted in a decreased DTH response to subcutaneously (s.c.) injected $\mathrm{OVA}_{323-339}$ and CFA in wild-type (WT) but not $\mathrm{Marco}^{-/-}$BALB/c mice (Fig. 2g) A role for MARCO in Tcell tolerance has not previously been defined. Thus, we further examined whether $\mathrm{MarCo}^{-/-}$ mice were resistant to other forms of tolerance induction. Similarly to WT mice, $\mathrm{Marco}^{-/-}$ mice could be tolerized by infusion of soluble $\mathrm{OVA}_{323-339}$ (Fig. $2 \mathrm{~h}$ ) or OVA $323-339^{-\mathrm{SP}}$ (Fig. 2i). Cumulatively, the data show the impor- tance of MARCO in T-cell tolerance induced by Ag-PSB. However, these findings indicate that soluble peptides and apoptotic $\mathrm{Ag}$-SP induce tolerance through different mechanisms that probably involve different antigen uptake receptors.

\section{T-cell extravasation}

We next determined the temporal and kinetic effects of Ag-PSB infusion on circulating T cells using DO11.10 OVA $_{323} 339$-specific T-cell receptor (TCR) transgenic mice and beads coupled to OVA $323-339$. We selected DO11.10 mice for this study to eliminate potential variables related to diverse TCR repertoires and/or the potential for self reactivity.

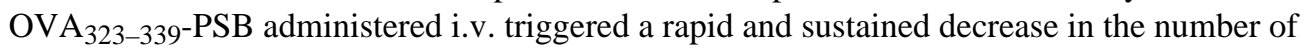

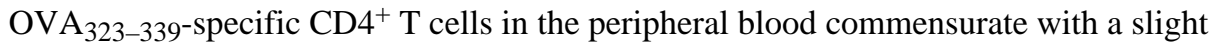
increase in the number of $\mathrm{T}$ cells in the spleen and lymph nodes (Fig. 3a and Supplementary Fig. 1). This reduction was antigen specific, as it was not induced by intravenous

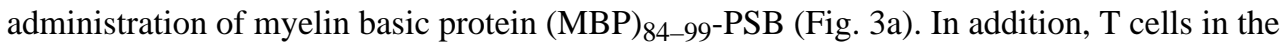
blood and secondary lymphoid organs of these mice showed functional differences. T cells isolated from the lymph nodes, but not from the blood, of DO11.10 mice that had been i.v. injected with $\mathrm{OVA}_{323-339}$-PSB were hypoproliferative in response to $\mathrm{OVA}_{323-339}$ stimulation (Fig. 3b, c). These data imply that $\mathrm{T}$-cell tolerance may require T-cell interaction with some cell populations located in the secondary lymphoid organs.

\section{Role of $T_{\text {reg }}$ cells and IL-10}

We have previously shown that the T-cell tolerance induced by intravenous administration of peptides crosslinked to splenic leukocytes was partially dependent on IL-10 and the activity of antigen-specific CD $4^{+} \mathrm{CD} 25^{+} \mathrm{Foxp}^{+} \mathrm{T}_{\text {reg }}$ cells ${ }^{12}$. Neutralization of IL-10 at the time of PLP $139-151$-PSB infusion had only a marginal effect on tolerance induction (Fig. $3 d)$. However, functional inactivation of $\mathrm{T}_{\text {reg }}$ cells by treatment with the CD25-specific antibody PC61 (ref. 25) before PLP $139-151$-PSB infusion resulted in a modest but significant $(P<0.05$, analysis of variance (ANOVA)) and reproducible reversal of the amount of protection during acute disease (Fig. 3e). These results suggest that regulatory $\mathrm{T}$ cells have an important, but redundant, role in PSB-induced tolerance, as treatment with CD25-specific antibodies only partially blocked tolerance induction. IL-10 seems to make only modest contributions to PSB-induced tolerance.

\section{T-cell abortive activation and anergy}

To further explore the effects of these microparticles on T-cell proliferation and differentiation, we adoptively transferred carboxyfluorescein diacetate succinimidyl diester (CFSE)-labeled PLP $139-151^{-}$-specific transgenic (5B6) T cells into naive SJL/J mice. Forty- 
eight hours later, we i.v. injected $9 \times 10^{9} \mathrm{PLP}_{139-151}$-PSB or $\mathrm{OVA}_{323-339-\mathrm{PSB} \text { or s.c. }}$

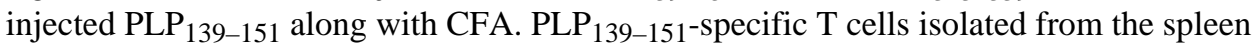
and lymph nodes of PLP $139-151$-PSB-treated mice showed markedly reduced proliferation (CFSE dilution) in terms of both the percentage of total cells divided and the number of divisions per cell compared to cells from mice injected with PLP ${ }_{139-151}$ plus CFA (Fig. 4aiiv). Notably, this effect was antigen specific, as T cells from mice injected with OVA $_{323-339}$-PSB did not show any CFSE dilution (Fig. 4av-vi). We injected a subset of mice first i.v. with PLP $139-151-\mathrm{PSB}$ or $\mathrm{OVA}_{323-339}$-PSB and then s.c. with $\mathrm{PLP}_{139-151}$ plus CFA. T cells from mice injected with PLP ${ }_{139-151-P S B}$ before PLP $_{139-151}$ plus CFA proliferated less than those from mice injected with PLP ${ }_{139-151}$ plus CFA alone (Fig. 4a, b).

The muted proliferation induced by peptide-coupled particle infusion suggests that tolerance may be induced by abortive T-cell activation. After adoptive transfer into naive $\mathrm{SJL} / \mathrm{J}$ mice, $\mathrm{PLP}_{139-151}$-specific $\mathrm{T}$ cells isolated from mice injected i.v. with $\mathrm{PLP}_{139-151}$-PSB showed classical T-cell activation phenotypes: upregulated expression of CD69 and CD44 and downregulated expression of CD62L (Fig. 5a, b). Notably, a larger fraction of splenic PLP $_{139-151}$-specific T cells expressed CD69 in mice injected i.v. with PLP $139-151-P S B$ than in mice injected s.c. with PLP ${ }_{139-151}$ plus CFA (Fig. 5a). However, the opposite was true with regard to CD44 expression (Fig. 5b). In addition, T cells in mice i.v. administered PLP $_{139-151}$-PSB produced neither interferon- $\gamma$ (IFN- $\gamma$ ) nor IL-17, whereas cells in mice injected s.c. with PLP $139-151$ and CFA produced both of these cytokines (Fig. 5c, d). Furthermore, $T$ cells from mice injected i.v. with PLP $139-151$-PSB produced minimal IL-17 and IFN- $\gamma$, even when the recipient mice were challenged s.c. with PLP ${ }_{139-151}$ plus CFA 5 d later (Fig. 5c, d); as shown by OVA $323-339$ injection, this effect was antigen specific. Together these findings suggest that PLP $139-151-\mathrm{PSB}$ induce abortive T-cell activation.

Anergy has been implicated in the induction of T-cell tolerance ${ }^{12,16}$. We thus examined a potential role for clonal anergy in $\mathrm{PLP}_{139-151}$-PSB tolerance. We i.v. injected SJL/J mice with OVA $_{323-339}$-PSB or PLP $139-151$-PSB and s.c. injected them with PLP $139-151$ and CFA $7 \mathrm{~d}$ later. We measured then the in vitro T-cell responses to various peptides and cytokines 8 d later. Compared to T cells from $\mathrm{OVA}_{323-339}$-PSB-injected mice, those from PLP $_{139-151^{-}}$ PSB-injected mice showed less proliferation and IFN- $\gamma$ and IL-17 production after in vitro re-stimulation with PLP $139-151$. However, these responses were significantly $(P<0.01$, ANOVA), but not completely, restored by the addition of exogenous IL-2 to the cultures. (Fig. 6a-c). Thus, antigenic peptides coupled to microparticles are capable of inducing Tcell anergy, which can be overcome in vitro through the addition of exogenous IL-2 (ref. 26).

\section{Biodegradable microparticles induce T-cell tolerance}

Our data highlight the ability of polystyrene microparticles to serve as antigen carriers to induce T-cell tolerance. To determine whether T-cell tolerance can also be induced with biocompatible, biodegradable microparticles, we tested particles made of the US Food and Drug Administration-approved material poly(lactide-co-glycolide) (PLG). PLG is stable and considered to be immunologically inert ${ }^{13}$. Similarly to PLP $139-151-\mathrm{PSB}, \mathrm{PLP}_{139-151}$-PLG administered i.v. localized to the splenic marginal zone (Fig. 6d, e). When administered prophylactically, PLP $_{139-151}$-PLG administered i.v. reduced EAE clinical scores and PLPspecific DTH responses (Fig. 6f-h). We were also able to treat ongoing EAE disease with i.v. administration of PLP $139-151$-PLG. (Fig. 6i).

We then tested whether microparticles coupled with the appropriate relapse-associated myelin epitopes could inhibit disease relapse when administered during disease remission. Intravenous administration of PLP $178-191-$ PLG $25 \mathrm{~d}$ after s.c. injection of PLP $139-151$ and 
CFA reduced the severity of relapse symptoms (Fig. 6j), as did infusion of PLP P $_{139-151}$-PLG $18 \mathrm{~d}$ after s.c. injection of PLP $178-191$ and CFA (Fig. 6k).

\section{DISCUSSION}

We found previously that antigenic peptides coupled to splenic leukocytes can be used as treatments in preclinical models of autoimmune disease, allergy and transplantation $12,18,27,28$. This technique is currently being evaluated in the clinic for treatment of multiple sclerosis (S.D.M., unpublished data). However, the complexity and cost of producing antigen-coupled cells under GMP conditions may impede clinical translation. We undertook the current study to determine whether inert microparticles could be used as surrogates for apoptotic leukocytes as antigen 'carriers'. Inert microparticles coupled to peptides, unlike Ag-SP, can be produced in large amounts under GMP conditions. We demonstrate that both polystyrene and biodegradable PLG microparticles are highly efficient substitutes for apoptotic cells, as they are taken up in a MARCO scavenger receptor-dependent fashion and are capable of inducing long-term antigen-specific T-cell abortive activation and anergy.

To avoid complications of immunosuppression, the ability to tolerize $\mathrm{T}$ cells specific for autoantigens and alloantigens remains the desired treatment for a myriad of immunemediated diseases. However, the translatability of the tolerance approaches demonstrated to be efficacious in animal studies has been lacking. Intravenous administration of anti-CD3 to induce tolerance in type 1 diabetes has resulted in questionable efficacy and safety concerns ${ }^{29}$. Attempts to potentially overcome some of these barriers through oral administration are under way, and some positive data have been obtained in small study involving 15 patients ${ }^{30}$. Initial studies using anti-CD3 to treat type 1 diabetes also showed similar positive outcomes ${ }^{29}$; therefore, larger patient studies will be needed to clearly define any clinical benefit of oral over intravenous anti-CD3 treatment.

A number of antigen-specific approaches to generate tolerance have previously been tested in autoimmune diseases. Intradermal administration of CGP77116, an altered peptide ligand of $\mathrm{MBP}_{83-99}$, worsened symptoms in three patients with multiple sclerosis because in at least two of the patients there were ${ }^{6}$ increased immune responses to $\mathrm{MBP}_{83-99}$. Attempts to induce 'high-zone tolerance' 31 by i.v. (MBP8298) infusion of a large bolus of peptide recently failed a phase 3 clinical trial in patients with multiple sclerosis ${ }^{32}$. Similarly, in type 1 diabetes, s.c. injection of the 65-kDa isoform of glutamic acid decarboxylase in alum had no effect on disease progression ${ }^{33}$. Mucosal antigen delivery has also shown promise in animal models of multiple sclerosis and type 1 diabetes $^{34}$, but larger clinical trials testing oral and nasal administration of insulin have been ineffective in the prevention or reversal of new-onset type 1 diabetes ${ }^{35,36}$.

Two DNA vaccines are also in development for treating patients with multiple sclerosis. BHT3009 encodes full-length MBP. In a phase 2 study, BHT3009 was administered at weeks 0,2 and 4 and then monthly by s.c. injection. Although this treatment did not alter the relative risk for relapse or first time to relapse, there was a reduction in new CNS lesions ${ }^{37}$. The reduction in lesion formation was most prominent in patients that had high concentrations of antibodies targeting MBP, whereas patients with low anti-MBP titers had a similar rate of lesion formation as placebo-treated controls. Although further studies are needed to confirm the potential utility of BHT3009, the existence of a patient population that may not be responsive to BHT3009 supports the need for other therapeutic modalities.

A second DNA vaccine, ATX-MS-1467, expresses peptides that are thought to mimic processed myelin antigens and therefore act similarly to glatiramer acetate (GLAT), a 
random-length polymer of four amino acids (glutamic acid, lysine, alanine and tyrosine) found in MBP, which has been shown to compete with myelin peptides for access to the peptide binding cleft in the MHC complex ${ }^{38}$, promote $\mathrm{T}_{\mathrm{H}} 2$ cell responses and induce IL-10producing $\mathrm{T}_{\text {reg }}$ cells ${ }^{39}$. These effects are not antigen specific, and as such, it may be predicted that the efficacy of ATX-MS-1467 may be similar to that of GLAT, resulting in a $50 \%$ reduction in multiple sclerosis relapses in responsive patients ${ }^{38}$.

Our data showing the requirement for peptides to be covalently linked to 500-nm particles and confirming the importance of i.v. administration for efficient tolerance induction ${ }^{12}$ reinforce the importance of delivering the antigen-linked particles to the splenic marginal zone. As a possible explanation of the particle size requirement, it has been reported that compared to 20-nm diameter particles, 200-nm and 1,000-nm diameter particles have a higher propensity to bind to MARCO in vitro ${ }^{40}$. We show that MARCO-expressing MZM, but not SIGLEC-1-expressing metallophilic macrophages, take up peptide-linked particles. To our knowledge, MARCO has not previously been ascribed a role in T-cell tolerance, although this receptor was previously implicated in the pathogenesis of systemic lupus erythematosus; in systemic lupus erythematosus, it is postulated that failure of MARCO to remove apoptotic debris has a potential role in autoantibody formation ${ }^{41,42}$. MARCO is also important for the uptake of bacteria ${ }^{43}$, silica particles ${ }^{44}$ and polymer-based microparticles $^{40}$. We speculate that MARCO functions through its ability to take up antigenlinked particles and assist in macrophage antigen presentation and/or antigen transfer to local dendritic cells. MARCO may also inhibit inflammatory responses by preventing dendritic cell migration ${ }^{45}$ or by other unknown anti-inflammatory mechanisms ${ }^{46}$. However, although macrophage production of IL-10 is thought to be crucial for tolerance to apoptotic cells $^{12}$, IL-10 neutralization failed to completely inhibit the tolerance induced by antigenic peptides coupled to microparticles. In addition, it seems that the MARCO pathway of tolerance induction is limited to microparticle-bound peptide, as $\mathrm{Marco}^{-/-}$mice were effectively tolerized to soluble peptide and peptides coupled to apoptotic splenic leukocytes.

PLP $_{139-151}$-PSB infusion triggered antigen-specific T-cell extravasation into the lymphoid compartment. This extravasation was notable, as T cells isolated from the peripheral blood but not the lymph nodes within $48 \mathrm{~h}$ after treatment remained highly reactive to self antigen. This is probably the result of the inability of $\mathrm{T}$ cells to interact with tolerogenic antigenpresenting cells and/or $\mathrm{T}_{\text {reg }}$ cells while in the laminar flow of the blood. In addition, $\mathrm{PLP}_{139-151}$-PSB infusion resulted in suboptimal PLP ${ }_{139-151}$-specific T-cell proliferation, cytokine production and activation in general. T-cell anergy was also induced, as nonresponsiveness could be largely reversed through the addition of exogenous IL-2 (refs. 26,47). Functional inactivation of $T_{\text {reg }}$ cells partially prevented the tolerance induced by antigenic peptide-coupled microparticles, which is in line with our previous studies using splenic leukocytes ${ }^{12}$. Upregulation of PD-L1 expression on splenic macrophages was implicated in our previous work, but we found only slight upregulation of PD-L1 expression on macrophages in mice treated with antigenic peptides coupled to microparticles (data not shown). Future experiments are required to further delineate the role of PD-L1 and CTLA-4 in antigen-coupled particle tolerance ${ }^{17}$.

Clinical translation of tolerance-based therapies for the treatment of autoimmune disease requires the ability to suppress pre-existing autoreactive effector $\mathrm{T}$ cells and/or establish tolerance of naive autoreactive $\mathrm{T}$ cells that may be activated after exposure to endogenous autoantigens released from damaged target organs (epitope spreading $)^{10}$. Here we show that i.v. administration of PLP $139-151-\mathrm{PSB}$ can prophylactically prevent R-EAE, inhibit established R-EAE and suppress relapse caused by epitope spreading. 
This study supports the use of antigen-coupled microparticles as a tool for tolerance induction. This option will probably have broad therapeutic utility, with preliminary studies in airway allergy ${ }^{27}$ and allotolerance ${ }^{18,28}$ yielding promising results. From a clinical development perspective, identification of specific autoantigens and T-cell epitopes to be targeted in various autoimmune diseases, and a determination of the roles of scavenger receptors in various diseases, remain challenges for further investigations.

\section{ONLINE METHODS}

Mice

Female SJL/J mice were purchased from Harlan Laboratories (Indianapolis, IN). Female $\mathrm{BALB} / \mathrm{c}$ mice were purchased from the Jackson Laboratory (Bar Harbor, ME). TCR transgenic mice expressing a TCR specific for $\mathrm{PLP}_{139-151}$ (5B6) on the SJL/J background were the kind gift of V. Kuchroo (Harvard) and were bred in-house at Northwestern University. $\mathrm{Marco}^{-/-}$mice on the BALB/c background were kindly provided by L. Kobzik (Harvard). All mice were housed under specific pathogen-free conditions in the Northwestern University Center for Comparative Medicine and maintained according to protocols approved by the Northwestern University Institutional Animal Care and Use Committee.

\section{Peptides}

PLP $_{139-151}$ (HSLGKWLGHPDKF), MOG $_{35-55}$ (MEVGWYRSPF SRVVHLYRNGK) and OVA $323-339$ (ISQAVHAAHAEINEAGR) were purchased from Genemed Synthesis. PLP $_{178-191}$ (NTWTTCQSIAFPSK) was purchased from Peptides International.

\section{Induction and clinical evaluation of peptide-induced EAE}

Peptide-induced and adoptive-transfer EAE was induced in SJL/J mice as previously reported ${ }^{48,49}$. Individual mice were observed daily, and clinical scores were assessed in a blinded fashion on a $0-5$ scale as follows: 0 , no abnormality; 1 , limp tail or hindlimb weakness; 2 , limp tail and hindlimb weakness; 3 , hindlimb paralysis; 4 , hindlimb paralysis and forelimb weakness; and 5, moribund. The data are reported as the mean daily clinical score. Paralyzed mice were given easier access to food and water.

\section{Tolerance induction with antigen-coupled cells and microparticles}

Tolerance was induced by i.v. injection of chemically treated Ag-SP, as described previously ${ }^{11,18}$. Briefly, spleens were removed from naive female mice, and the red blood cells were lysed. The splenocytes were incubated with ECDI $\left(150 \mathrm{mg}\right.$ per $3.2 \times 10^{8}$ cells; Calbiochem) and peptide $(1 \mathrm{mg} / \mathrm{ml})$ on ice, shaking for $1 \mathrm{~h}$. The coupled cells were washed three times and filtered through a $70-\mu \mathrm{M}$ cell strainer to remove cell clumps. The Ag-SP were resuspended at $250 \times 10^{6} \mathrm{cells} / \mathrm{ml}$ in PBS. Each mouse received $50 \times 10^{6} \mathrm{Ag}-\mathrm{SP}$ in $200 \mu l$ of PBS given by i.v. injection at the indicated times before disease induction. This dosage represents delivery of a total of $15-20 \mu \mathrm{g}$ of cell-bound peptide per mouse. Carboxylated PSB of various diameters were purchased from Polysciences (Warrington, PA). Peptide antigens were attached to particles using ECDI according to manufacturer's instructions $(12.5 \mathrm{mg}$ of polystyrene microparticles and $500 \mu \mathrm{g}$ of peptide in the presence of $10 \mathrm{mg} / \mathrm{ml} \mathrm{ECDI}$ ). Five-hundred-nanometer carboxylated PLG microparticles were purchased from Phosphorex, Inc. (Fall River, MA), and peptide antigens were attached using ECDI as for the PSB. Mice received intravenous injections of approximately $9 \times 10^{9}$ microparticles comprising 15-20 $\mu \mathrm{g}$ of peptide, depending on the sequence used in the coupling reaction. 


\section{Antibodies and flow cytometry}

Cells were isolated from the spleen or CNS as previously described ${ }^{49}$. Briefly, FcR blocking with CD16/32 (clone 2.4G2) was performed, followed by staining with various combinations of antibodies to the following: CD69 (clone H1.2F3)-allophycocyanin (APC), CD69-FITC, CD62L (clone MEL14)-APC/AlexaFluor750, CD44 (clone IM7)phycoerythrin (PE)/Cy7, Foxp3 (clone FJK-16s)-APC, Foxp3-PE/Cy7, CD152 (clone UC10-4B9)-PE, PD-L1 (clone MIH5)-PE, IFN- $\gamma$ (clone XMG1.2)-PE/Cy7, IL-17 (clone eBio17B7)-APC, CD90.1 (clone HIS51)-Pacific Blue and CD45 (clone 30-F11)-PE, all of which were purchased from eBioscience. CD25 (clone PC61)-FITC and CD25-APC, CD3 (clone 145.2C11)-APC-Alexa750 and CD4 (clone GK1.5)-PerCP were purchased from Becton-Dickinson. Cytometric data were collected on a FACS Canto flow cytometer (Becton-Dickinson). DiVa software was used for data acquisition and analysis (BectonDickinson).

\section{DTH and in vitro proliferation assays}

DTH was performed by a $24 \mathrm{~h}$ ear swelling assay as previously reported ${ }^{11}$. Prechallenge ear thickness was determined using a Mitutoyo model 7326 engineer's micrometer (Schlesinger's Tools, Brooklyn, New York). Immediately after, DTH responses were elicited by injecting $10 \mu \mathrm{g}$ of peptide in $10 \mu \mathrm{l}$ of PBS into the dorsal surface of the ear using a $100-\mu 1$ Hamilton syringe fitted with a 30 gauge needle. The increase in ear thickness over the prechallenge measurements was determined $24 \mathrm{~h}$ after ear challenge. Results are expressed in units of $10^{-4}$ inches \pm s.e.m. For proliferation assays, draining lymph nodes (axillary, brachial and inguinal) and/or spleens were harvested from naive mice or primed mice at the indicated times after disease induction, counted and cultured in 96-well microtiter plates at a density of $5 \times 10^{5}$ cells per well in a total volume of $200 \mu 1$ of HL-1 medium (BioWhittaker; $1 \%$ penicillin and streptavidin and $1 \%$ glutamine). Cells were cultured at $37^{\circ} \mathrm{C}$ with medium alone or with different concentrations of peptide antigen for $72 \mathrm{~h}$. During the last $24 \mathrm{~h}$, cultures were pulsed with $1 \mu \mathrm{Ci}$ per well $\left[{ }^{3} \mathrm{H}\right] \mathrm{TdR}$, and uptake was detected using a Topcount microplate scintillation counter. Results are expressed as the mean of triplicate cultures. IFN- $\gamma$ and IL-17 concentrations were determined by Liqui-Chip analysis.

\section{$\mathbf{T}_{\text {reg }}$ cell inactivation}

$\mathrm{T}_{\text {reg }}$ cell inactivation was performed by injection of $500 \mu \mathrm{g}$ per mouse anti-CD25 (clone PC61) as described previously ${ }^{25}$.

\section{T cell transfer assays}

Naive $\mathrm{T}$ cells were isolated from the lymph nodes of healthy $5 \mathrm{~B} 6$ mice by magnetic separation. Single-cell preparations of nodes were prepared, FcR blocked with $2.4 \mathrm{G} 2$ and labeled with $\mathrm{CD}^{+} \mathrm{T}$ cell isolation reagents (Miltenyi Biotec). T cells were isolated using an AutoMACS magnetic separator (Miltenyi Biotec). Ninety-four to ninety-eight percent purity was routinely achieved. After isolation, $20 \times 10^{6} \mathrm{~T}$ cells per $\mathrm{ml}$ were fluorescently labeled in a $4 \mu \mathrm{M}$ solution of carboxyfluorescein diacetate in PBS for $8 \mathrm{~min}$ at room temperature. The reaction was quenched by addition of a half volume of heat-inactivated FBS and an additional 5 min incubation at room temperature. Cells were washed twice in PBS before injection into the lateral tail vein of recipient mice $\left(5 \times 10^{6} \mathrm{~T}\right.$ cells per recipient). Forty-eight hours after transfer, recipient mice were treated with a variety of antigen-coupled microparticles or with antigen in CFA. At various times after treatment, spleens and lymph nodes were isolated, and transgenic T cells (identifiable by CD90.1 and transgene expression) in these organs were analyzed for cell division and a variety of surface and intracellular markers as described above. 


\section{Immunohistochemistry}

Mice were infused with PBS or FITC-labeled $\mathrm{MOG}_{35-55}-\mathrm{PSB}$. Eighteen hours after infusion, spleens were dissected, fixed in paraformaldehyde for $30 \mathrm{~min}$ to $3 \mathrm{~h}$ at $4{ }^{\circ} \mathrm{C}$ in the dark and snap frozen in optimal cutting temperature compound. The blocks were stored at $-80{ }^{\circ} \mathrm{C}$ in plastic bags to prevent dehydration. Six-micrometer-thick cross-sections were cut on a Reichert-Jung Cryocut CM1850 cryotome (Leica), mounted on Superfrost Plus electrostatically charged slides (Fisher), air dried and stored at $-80^{\circ} \mathrm{C}$. Slides were stained using the Tyramide Signal Amplification Direct kit (NEN) according to the manufacturer's instructions. Nonspecific staining was blocked using either Ab that recognizes both CD16 and CD32 (FcIII/IIR, 2.4G2; BD Pharmingen) or 10\% horse serum, as well as an avidin and biotin blocking kit (Vector Laboratories) in addition to the blocking reagent provided by the Tyramide Signal Amplification kit (NEN). Sections were then stained with primary [MARCO (BAF2956), SIGN-R1 (BAF1836) or SIGLEC-1 (BAF5610)] and secondary antibodies, as well as DAPI as previously described ${ }^{12}$. Sections were coverslipped with Vectashield mounting medium with DAPI (Vector Laboratories), and images were acquired using a Lica DM5000B fluorescent microscope and Advanced SPOT software. At least eight serial sections from each sample per group were analyzed at $\times 20, \times 40$ and $\times 100$ magnification.

\section{Statistical analyses}

Comparisons of DTH responses, mean clinical disease scores, proliferation, cytokine responses or mean fluorescence intensities between any two groups of mice were analyzed by a standard two-tailed $t$ test or one-way ANOVA, depending on the precise comparisons made. $P<0.05$ was considered significant.

\section{Supplementary Material}

Refer to Web version on PubMed Central for supplementary material.

\section{Acknowledgments}

This work was supported by a grant from the Myelin Repair Foundation, US National Institutes of Health grants NS026543 and EB013198, Juvenile Diabetes Research Foundation grant 17-2011-343 and the Australian National Health and Medical Research Council grants 512413 and 1030897. We also thank V. Kuchroo and L. Kobchik of Harvard University for providing transgenic mice.

\section{References}

1. Christen U, von Herrath MG. Initiation of autoimmunity. Curr Opin Immunol. 2004; 16:759-767. [PubMed: 15511670]

2. Chatenoud L, Bluestone JA. CD3-specific antibodies: a portal to the treatment of autoimmunity. Nat Rev Immunol. 2007; 7:622-632. [PubMed: 17641665]

3. Kohm AP, Turley DM, Miller SD. Targeting the TCR: T-cell receptor and peptide-specific tolerance-based strategies for restoring self-tolerance in CNS autoimmune disease. Int Rev Immunol. 2005; 24:361-392. [PubMed: 16318987]

4. Miller SD, Turley DM, Podojil JR. Antigen-specific tolerance strategies for the prevention and treatment of autoimmune disease. Nat Rev Immunol. 2007; 7:665-677. [PubMed: 17690713]

5. Herold KC, et al. Treatment of patients with new onset Type 1 diabetes with a single course of antiCD3 mAb Teplizumab preserves insulin production for up to 5 years. Clin Immunol. 2009; 132:166-173. [PubMed: 19443276]

6. Bielekova B, et al. Encephalitogenic potential of the myelin basic protein peptide (amino acids 8399) in multiple sclerosis: results of a phase II clinical trial with an altered peptide ligand. Nat Med. 2000; 6:1167-1175. [PubMed: 11017150] 
7. Papadopoulou A, et al. Evolution of MS lesions to black holes under DNA vaccine treatment. J Neurol. 2012; 259:1375-1382. [PubMed: 22222856]

8. Freedman MS, et al. A phase III study evaluating the efficacy and safety of MBP8298 in secondary progressive MS. Neurology. 2011; 77:1551-1560. [PubMed: 21975206]

9. Smith CE, Eagar TN, Strominger JL, Miller SD. Differential induction of IgE-mediated anaphylaxis after soluble vs. cell-bound tolerogenic peptide therapy of autoimmune encephalomyelitis. Proc Natl Acad Sci USA. 2005; 102:9595-9600. [PubMed: 15983366]

10. Vanderlugt CL, et al. Pathologic role and temporal appearance of newly emerging autoepitopes in relapsing experimental autoimmune encephalomyelitis. J Immunol. 2000; 164:670-678. [PubMed: 10623809]

11. Turley DM, Miller SD. Peripheral tolerance Induction using ethylenecarbodiimide-fixed APCs uses both direct and indirect mechanisms of antigen presentation for prevention of experimental autoimmune encephalomyelitis. J Immunol. 2007; 178:2212-2220. [PubMed: 17277126]

12. Getts DR, et al. Tolerance induced by apoptotic antigen-coupled leukocytes is induced by PD-L1+ and IL-10-producing splenic macrophages and maintained by T regulatory cells. J Immunol. 2011; 187:2405-2417. [PubMed: 21821796]

13. Tyner K, Sadrieh N. Considerations when submitting nanotherapeutics to FDA/CDER for regulatory review. Methods Mol Biol. 2011; 697:17-31. [PubMed: 21116951]

14. Zolnik BS, Gonzalez-Fernandez A, Sadrieh N, Dobrovolskaia MA. Nanoparticles and the immune system. Endocrinology. 2010; 151:458-465. [PubMed: 20016026]

15. Viorritto IC, Nikolov NP, Siegel RM. Autoimmunity versus tolerance: can dying cells tip the balance? Clin Immunol. 2007; 122:125-134. [PubMed: 17029966]

16. Eagar TN, et al. CTLA-4 regulates expansion and differentiation of Th1 cells following induction of peripheral T cell tolerance. J Immunol. 2004; 172:7442-7450. [PubMed: 15187122]

17. Fife BT, et al. Interactions between PD-1 and PD-L1 promote tolerance by blocking the TCRinduced stop signal. Nat Immunol. 2009; 10:1185-1192. [PubMed: 19783989]

18. Luo X, et al. ECDI-fixed allogeneic splenocytes induce donor-specific tolerance for long-term survival of islet transplants via two distinct mechanisms. Proc Natl Acad Sci USA. 2008; 105:14527-14532. [PubMed: 18796615]

19. Areschoug T, Gordon S. Scavenger receptors: role in innate immunity and microbial pathogenesis. Cell Microbiol. 2009; 11:1160-1169. [PubMed: 19388903]

20. Dahl M, et al. Protection against inhaled oxidants through scavenging of oxidized lipids by macrophage receptors MARCO and SR-AI/II. J Clin Invest. 2007; 117:757-764. [PubMed: 17332894]

21. Palecanda A, et al. Role of the scavenger receptor MARCO in alveolar macrophage binding of unopsonized environmental particles. J Exp Med. 1999; 189:1497-1506. [PubMed: 10224290]

22. Kraal G, Ter Hart H, Meelhuizen C, Venneker G, Claassen E. Marginal zone macrophages and their role in the immune response against T-independent type 2 antigens: modulation of the cells with specific antibody. Eur J Immunol. 1989; 19:675-680. [PubMed: 2471648]

23. Lyszkiewicz M, et al. SIGN-R1+MHC II+ cells of the splenic marginal zone-a novel type of resident dendritic cells. J Leukoc Biol. 2011; 89:607-615. [PubMed: 21208895]

24. Kang YS, et al. SIGN-R1, a novel C-type lectin expressed by marginal zone macrophages in spleen, mediates uptake of the polysaccharide dextran. Int Immunol. 2003; 15:177-186. [PubMed: 12578847]

25. Kohm AP, et al. Cutting Edge: Anti-CD25 mAb injection results in the functional inactivation, not depletion of CD4 ${ }^{+} \mathrm{CD} 25^{+}$Treg cells. J Immunol. 2006; 176:3301-3305. [PubMed: 16517695]

26. Beverly B, Kang SM, Lenardo MJ, Schwartz RH. Reversal of in vitro T cell clonal anergy by IL-2 stimulation. Int Immunol. 1992; 4:661-671. [PubMed: 1616898]

27. Smarr CB, Hsu CL, Byrne AJ, Miller SD, Bryce PJ. Antigen-fixed leukocytes tolerize Th2 responses in mouse models of allergy. J Immunol. 2011; 187:5090-5098. [PubMed: 21976774]

28. Martin AJ, et al. Ethylenecarbodiimide-treated splenocytes carrying male CD4 epitopes confer Hya transplant protection by inhibiting CD154 upregulation. J Immunol. 2010; 185:3326-3336.

[PubMed: 20713889] 
29. Herold KC, et al. A single course of anti-CD3 monoclonal antibody hOKT3gamma1(Ala-Ala) results in improvement in C-peptide responses and clinical parameters for at least 2 years after onset of type 1 diabetes. Diabetes. 2005; 54:1763-1769. [PubMed: 15919798]

30. Ilan Y, et al. Oral administration of OKT3 monoclonal antibody to human subjects induces a dosedependent immunologic effect in T cells and dendritic cells. J Clin Immunol. 2010; 30:167-177. [PubMed: 19756989]

31. Liblau RS, et al. High-dose soluble antigen: peripheral T-cell proliferation or apoptosis. Immunol Rev. 1994; 142:193-208. [PubMed: 7698794]

32. Fontoura P, Garren H. Multiple sclerosis therapies: molecular mechanisms and future. Results Probl Cell Differ. 2010; 51:259-285. [PubMed: 20838962]

33. Ludvigsson J, et al. GAD65 antigen therapy in recently diagnosed type 1 diabetes mellitus. N Engl J Med. 2012; 366:433-442. [PubMed: 22296077]

34. Chen Y, Kuchroo VK, Inobe J, Hafler DA, Weiner HL. Regulatory T cell clones induced by oral tolerance: suppression of autoimmune encephalomyelitis. Science. 1994; 265:1237-1240. [PubMed: 7520605]

35. Luo X, Herold KC, Miller SD. Immunotherapy of type 1 diabetes: where are we and where should we be going? Immunity. 2010; 32:488-499. [PubMed: 20412759]

36. Sherr J, Sosenko J, Skyler JS, Herold KC. Prevention of type 1 diabetes: the time has come. Nat Clin Pract Endocrinol Metab. 2008; 4:334-343. [PubMed: 18446141]

37. Garren $\mathrm{H}$, et al. Phase 2 trial of a DNA vaccine encoding myelin basic protein for multiple sclerosis. Ann Neurol. 2008; 63:611-620. [PubMed: 18481290]

38. Racke MK, Lovett-Racke AE. Glatiramer acetate treatment of multiple sclerosis: an immunological perspective. J Immunol. 2011; 186:1887-1890. [PubMed: 21289312]

39. Lalive PH, et al. Glatiramer acetate in the treatment of multiple sclerosis: emerging concepts regarding its mechanism of action. CNS Drugs. 2011; 25:401-414. [PubMed: 21476611]

40. Kanno S, Furuyama A, Hirano S. A murine scavenger receptor MARCO recognizes polystyrene nanoparticles. Toxicol Sci. 2007; 97:398-406. [PubMed: 17361018]

41. Chen XW, et al. Anti-class a scavenger receptor autoantibodies from systemic lupus erythematosus patients impair phagocytic clearance of apoptotic cells by macrophages in vitro. Arthritis Res Ther. 2011; 13:R9. [PubMed: 21281474]

42. Kranich J, et al. Follicular dendritic cells control engulfment of apoptotic bodies by secreting Mfge8. J Exp Med. 2008; 205:1293-1302. [PubMed: 18490487]

43. Thelen $\mathrm{T}$, et al. The class A scavenger receptor, macrophage receptor with collagenous structure, is the major phagocytic receptor for Clostridium sordellii expressed by human decidual macrophages. J Immunol. 2010; 185:4328-4335. [PubMed: 20810988]

44. Thakur SA, Hamilton R Jr, Pikkarainen T, Holian A. Differential binding of inorganic particles to MARCO. Toxicol Sci. 2009; 107:238-246. [PubMed: 18836211]

45. Arredouani MS, et al. Scavenger Receptors SR-AI/II and MARCO limit pulmonary dendritic cell migration and allergic airway inflammation. J Immunol. 2007; 178:5912-5920. [PubMed: 17442975]

46. Ghosh S, Gregory D, Smith A, Kobzik L. MARCO regulates early inflammatory responses against influenza: A useful macrophage function with adverse outcome. Am J Respir Cell Mol Biol. 2011; 45:1036-1044. [PubMed: 21562316]

47. DeSilva DR, Urdahl KB, Jenkins MK. Clonal anergy is induced in vitro by T cell receptor occupancy in the absence of proliferation. J Immunol. 1991; 147:3261-3267. [PubMed: 1658142]

48. Bailey SL, Schreiner B, McMahon EJ, Miller SD. CNS myeloid DCs presenting endogenous myelin peptides 'preferentially' polarize $\mathrm{CD} 4(+) \mathrm{T}(\mathrm{H})-17$ cells in relapsing EAE. Nat Immunol. 2007; 8:172-180. [PubMed: 17206145]

49. Schreiner B, Bailey SL, Shin T, Chen L, Miller SD. PD-1 ligands expressed on myeloid-derived APC in the CNS regulate T-cell responses in EAE. Eur J Immunol. 2008; 38:2706-2717. [PubMed: 18825752] 

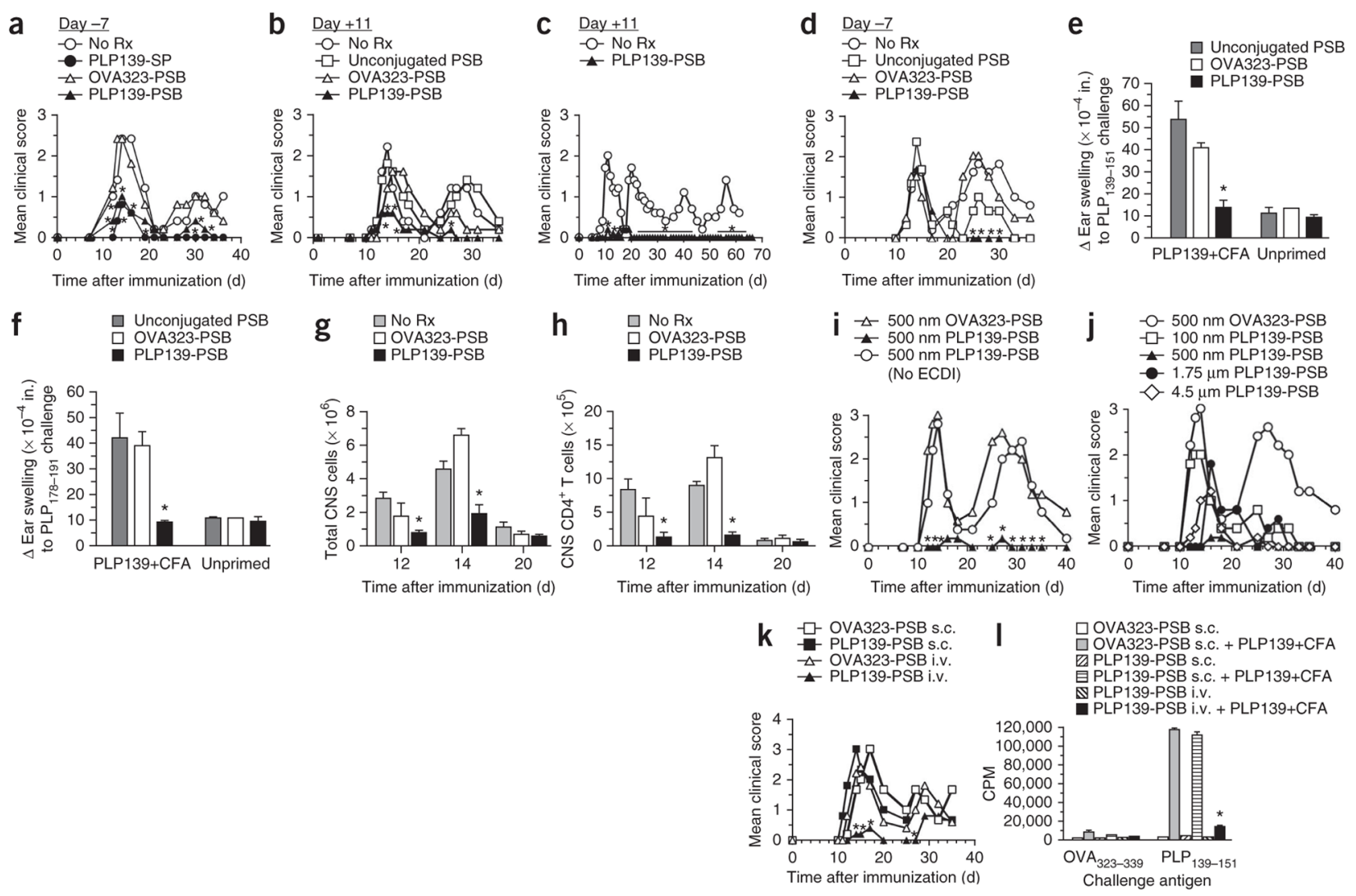

Figure 1.

Antigen-coupled polystyrene microparticles are effective for inducing tolerance for the prevention and treatment of EAE. (a) Mean clinical score of SJL/J mice injected i.v. with 500-nm carboxylated PSB coupled to PLP ${ }_{139-151}$ (PLP139-PSB) or OVA $323-339$ (OVA323PSB) $7 \mathrm{~d}$ before initiation of EAE by s.c. immunization with PLP ${ }_{139-151}$ plus CFA. A separate group was tolerized with PLP $139-151-\mathrm{SP}$ (PLP139-SP). No Rx, no treatment. (b,c) Mean clinical score of mice that received PLP $139-151-\mathrm{PSB}, \mathrm{OVA}_{323-339-\mathrm{PSB} \text { or }}$ unconjugated PSB at the onset of hindlimb paralysis (11 d after priming); disease symptoms were scored for a total of 35 and $66 \mathrm{~d}$, respectively. (d) Mean clinical score of mice injected i.v. with 500-nm carboxylated PSB coupled to PLP $_{139-151}$, OVA $323-339$ or nothing $7 \mathrm{~d}$ before induction of EAE with PLP $178-191$. $(\mathbf{e}, \mathbf{f})$ Ear swelling, as a measure of DTH, $24 \mathrm{~h}$ after ear challenge with the priming PLP $139-151$ epitope (e) or the PLP $_{178-191}$ spread epitope (f) at $36 \mathrm{~d}$ after priming in selected representative mice from the PLP $139-151$ plus CFA (PLP139+CFA)-primed groups in a (OVA $323-339-\mathrm{PSB}, \mathrm{PLP}_{139-151}$-PSB and no particles). Additional mice included in this analysis received doses of PSB i.v. but were not primed for EAE. Responses to a control OVA $323-339$ peptide were subtracted from each measure of ear swelling. (g,h) The number of CD45 ${ }^{\text {hi }}$ cells $(\mathbf{g})$ and $\mathrm{CD}^{+} \mathrm{CD}^{+} \mathrm{T}$ cells $(\mathbf{h})$ determined by flow cytometry at the onset of disease (day 12), peak of disease (day 14) and remission (day 20 ) in the brains and spinal cords of SJL/J mice injected i.v. with 500-nm carboxylated PSB coupled with PLP $139-151$, OVA $_{323-339}$ or nothing $7 \mathrm{~d}$ before EAE priming with PLP ${ }_{139-151}$ plus CFA. (i) Mean clinical score in SJL/J mice treated with i.v. injection of 500-nm carboxylated PSB incubated with PLP $139-151$ in the presence or absence of ECDI or treated with 500-nm OVA $323-339$-PSB $7 \mathrm{~d}$ before priming with PLP ${ }_{139-151}$ plus CFA. (j) Mean clinical score in SJL/J mice treated i.v. with PSB of varying diameters $(100 \mathrm{~nm}, 500 \mathrm{~nm}$, $1.75 \mu \mathrm{m}$ or $4.5 \mu \mathrm{m}$ ) coupled to PLP $139-151$ or treated with 500-nm OVA $323-339$-PSB $7 \mathrm{~d}$ 
before priming with PLP $_{139-151}$ plus CFA. (k) Mean clinical score in SJL/J mice treated with 500-nM PLP $139-151-\mathrm{PSB}$ or $\mathrm{OVA}_{323-339}$-PSB in the lateral tail vein (i.v.) or on the flank (s.c.) $7 \mathrm{~d}$ before priming with $\mathrm{PLP}_{139-151}$ plus CFA. (I) In vitro proliferative responses to stimulation with the $\mathrm{PLP}_{139-151}$ priming epitope or a control peptide (OVA $\left.323-339\right)$ determined by $\left[{ }^{3} \mathrm{H}\right]$-thymidine uptake in spleens and lymph nodes collected from a subset of the mice in k. CPM, counts per minute. All experiments consisted of 5-10 mice per group and are representative of $2-4$ repeats. ${ }^{*} P \leq 0.05$ (ANOVA) for the differences in mean clinical scores, DTH responses, numbers of CNS-infiltrating cells or proliferative responses compared to the responses in groups tolerized to the appropriate irrelevant control peptide. Error bars, s.e.m. 

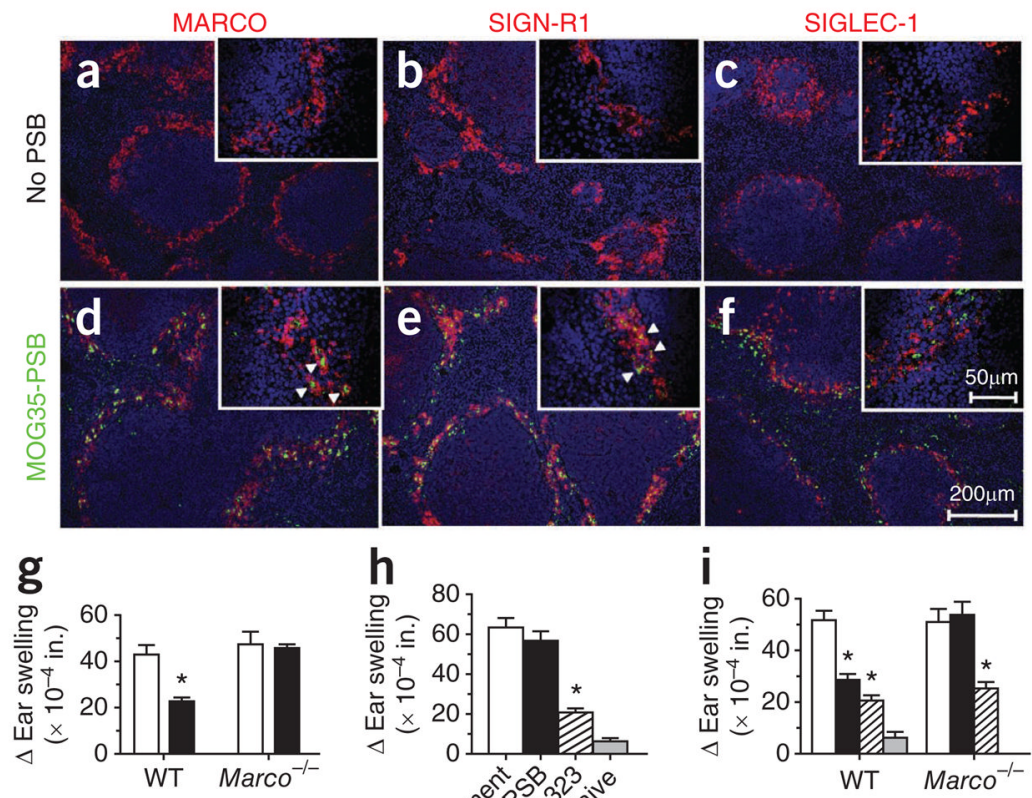

$\square$ MOG35-PSB $\square$ OVA323-SP

- OVA323-PSB $\square$ Naive

Figure 2.

MARCO has a crucial role in tolerance induction using antigen-coupled microparticles. (af) MARCO (a,d, red), SIGN-R1 (b,e, red), SIGLEC-1 (c,f, red) and 4,6-diamidino-2phenylindole (DAPI, blue) staining in dissected and snap-frozen spleens from mice infused with PSB (no PSB) or FITC-labeled $\mathrm{MOG}_{35-55}$-PSB (MOG35-PSB, green). Arrowheads indicate phagocytized PSB. (g) Ear swelling $24 \mathrm{~h}$ after ear challenge with $\mathrm{OVA}_{323-339}$ or an irrelevant peptide ( $\mathrm{PLP}_{129-151}$ ) in WT or $\mathrm{Marco}^{-/-} \mathrm{BALB} / \mathrm{c}$ mice injected i.v. with $\mathrm{OVA}_{323-339-P S B}$ (OVA323-PSB) or control MBP $84-104-\mathrm{PSB}$ (MBP84-PSB) $7 \mathrm{~d}$ before immunization with $\mathrm{OVA}_{323-339}$ plus CFA. Ear challenge, as a measure of DTH, was performed $8 \mathrm{~d}$ after immunization. (h,i) Ear swelling as described for $\mathbf{g}$ in WT (i) and $\mathrm{Marco}^{-1-}(\mathbf{h}, \mathbf{i}) \mathrm{BALB} / \mathrm{c}$ mice treated i.v. with OVA $323-339-\mathrm{PSB}(\mathbf{h}, \mathbf{i})$, soluble OVA $323-339$ (sol. OVA323) (h), $\mathrm{MOG}_{35-55}$-PSB (i) or OVA $323-339$-SP (i) 7-8 d before immunization with OVA $323-339$ plus CFA. All experiments consisted of 5-10 mice per group and are representative of at least $2-4$ separate experiments. $* P \leq 0.05$ (ANOVA) for differences in mean clinical scores and DTH responses compared to the responses in groups tolerized to the appropriate irrelevant control peptide. Error bars, s.e.m. 

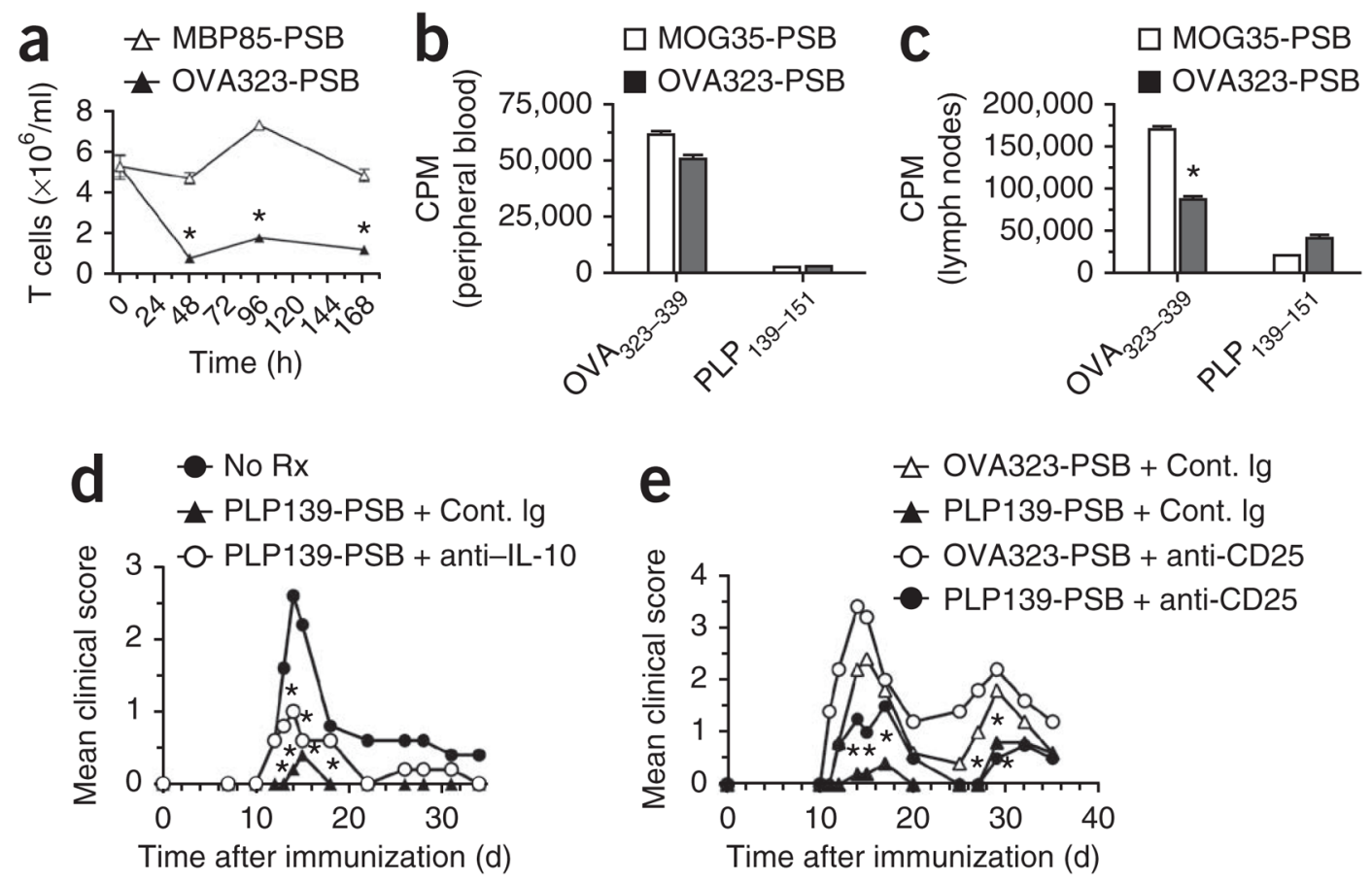

Figure 3.

Response of antigen-specific $\mathrm{T}$ cells to tolerance induction with Ag-PSB. (a) $\mathrm{T}$ cell content 48,39 and $168 \mathrm{~h}$ after treatment in female DO11.10 OVA 323 -339-specific TCR transgenic mice treated i.v. with 500-nm carboxylated PSB coupled to the cognate peptide (OVA $323-339$, OVA323-PSB) or an irrelevant peptide (MBP $\left.{ }_{85-99}, \mathrm{MBP} 85-\mathrm{PSB}\right)$. (b,c) Proliferation, measured by $\left[{ }^{3} \mathrm{H}\right]$-thymidine uptake, in $3 \times 10^{5} \mathrm{~T}$ cells magnetically purified from peripheral blood (b) and peripheral lymph nodes (c) of DO11.10 mice treated i.v. with 500-nm carboxylated PSB coupled to the cognate peptide $\left(\mathrm{OVA}_{323-339)}\right)$ or an irrelevant peptide (MOG $\left.{ }_{35-55}, \mathrm{MOG} 35-\mathrm{PSB}\right)$ and re-stimulated $48 \mathrm{~h}$ later with $1 \mathrm{mg} \mathrm{ml}^{-1}$ cognate OVA $_{323-339}$ peptide or $\mathrm{PLP}_{139-151}$ in vitro. (d,e) Mean clinical score in naive SJL/J mice treated with control immunoglobulin (Cont. Ig) or anti-IL-10 (JES5-16E3; $200 \mu \mathrm{g}$ intraperitoneally (i.p.)) (d) or control immunoglobulin or anti-CD25 (PC61; $500 \mu$ g i.p.) (e) $1 \mathrm{~d}$ before and $1 \mathrm{~d}$ after treatment with either OVA $323-339-$ PSB or PLP $139-151$-PSB (PLP139-PSB); $7 \mathrm{~d}$ after tolerization, mice were primed for EAE with PLP $139-151$ plus CFA. Data are representative of three separate experiments. Error bars, s.e.m. $* P \leq 0.05$ (Student's $t$ test) for the differences in T cell numbers, CPM and mean clinical scores compared to the responses in groups tolerized to the appropriate irrelevant control peptide. 
a

Spleen (day 5 P.I.)

LNs (day 5 P.I.)

b

Ns (day 5)

(n)

Spleen (day 5 P.I.)

(

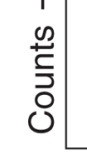

PLP $_{139-151}$-PSB i.v. PLP ${ }_{139-151}+$ CFA s.c. $\quad$ OVA $_{323-339}$-PSB i.v.
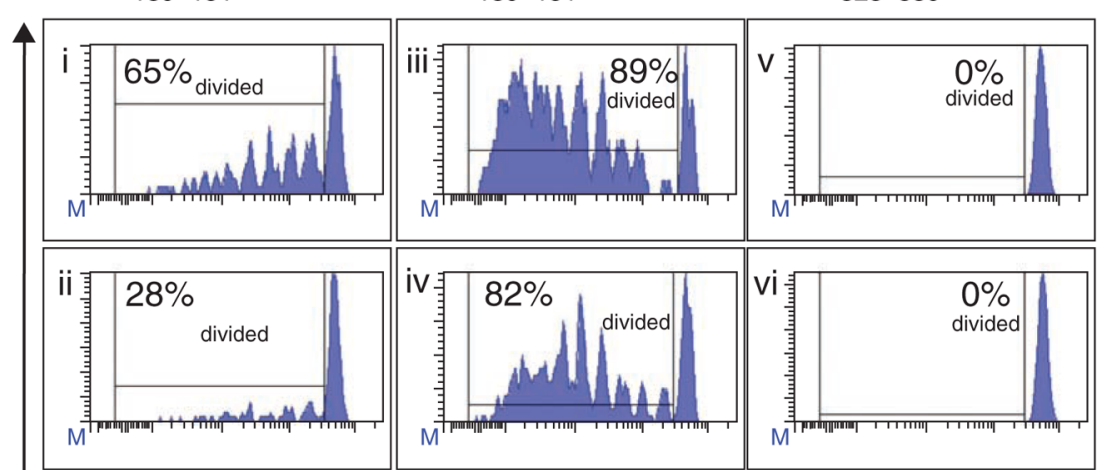

$$
\begin{aligned}
& \mathrm{PLP}_{139-151}-\mathrm{PSB}+ \\
& \mathrm{PLP}_{139-151}+\mathrm{CFA}
\end{aligned}
$$

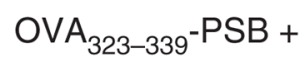

$$
\mathrm{PLP}_{139-151}+\mathrm{CFA}
$$
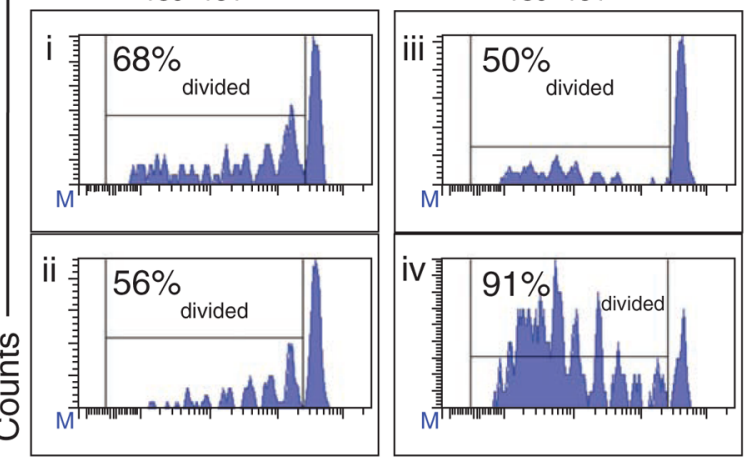

CFSE

Figure 4.

Antigen-specific T cells undergo suboptimal proliferation in response to Ag-PSB. (a) Results from naive SJL/J (CD90.2+) recipient mice exposed i.v. to PLP $_{139-151}$-PSB (i,ii),

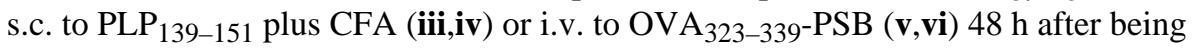
transferred with naive CD90.1 ${ }^{+}$PLP $_{139-151}$-specific 5B6 TCR transgenic T cells sorted from donor lymph nodes and labeled with CFSE. Five days after these treatments (P.I.), spleens and lymph nodes (LNs) were collected, and the percentage of diving CD90.1 $1^{+} \mathrm{T}$ cells was assessed by measuring CFSE dilution using flow cytometry. (b) Flow cytometric analyses of CFSE dilution at $5 \mathrm{~d}$ after priming in mice additionally treated with $\mathrm{PLP}_{139-151}-\mathrm{PSB}(\mathbf{i}, \mathbf{i i})$ or

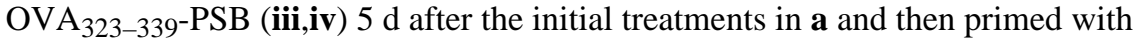
PLP $_{139-151}$ plus CFA. Three separate mice were analyzed in each group with representative plots shown. Data shown are representative of three separate experiments. Percentages in graphs reflect the percent of $\mathrm{T}$ cells that have divided. 


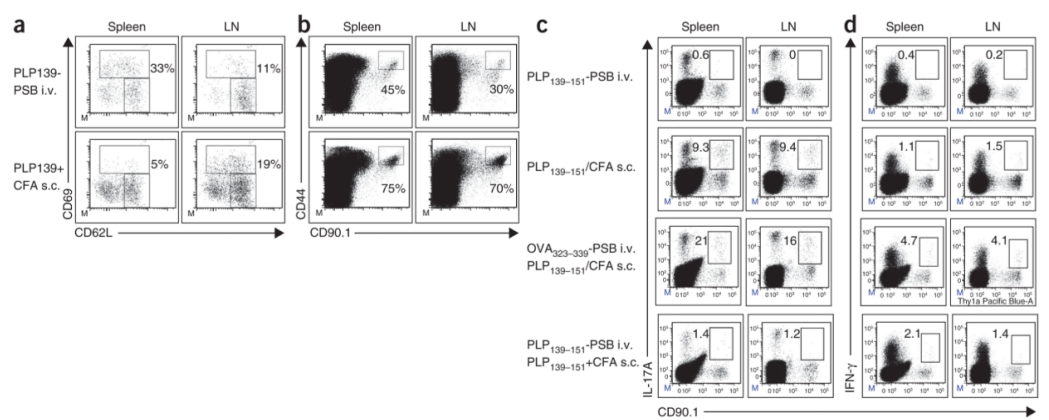

Figure 5.

Antigen-specific T cells are abortively activated after Ag-PSB encounter but do not synthesize IL-17A and IFN- $\gamma$ after direct in vivo exposure to Ag-PSB or after subsequent immunogenic stimulation. (a,b) Flow cytometric analyses of T-cell activation markers CD62L, CD69 and CD44 $5 \mathrm{~d}$ after treatment in spleens and lymph nodes (LNs) from naive CD90.2 $2^{+} \mathrm{SJL} / \mathrm{J}$ recipients after being transferred with CFSE-labeled naive CD90.1 ${ }^{+} 5 \mathrm{~B} 6$ TCR transgenic T cells and then treated i.v. with PLP $139-151$-PSB (PLP139-PSB) or primed s.c. with PLP $139-151$ plus CFA. Transgenic T cells were identified by CD90.1 and CFSE signals. (c,d) Naive CD90.1 ${ }^{+}$5B6 TCR transgenic T cells were CFSE labeled and transferred to naive $\mathrm{CD} 90.2^{+} \mathrm{SJL} / \mathrm{J}$ recipients that were then treated i.v. with $\mathrm{PLP}_{139-151^{-}}$ PSB or primed s.c. with PLP $139-151$ plus CFA. Five days after treatment, levels of intracellular IL-17A (c) and IFN-gamma (d) were determined. Where indicated, SJL/J recipients of naive CFSE-labeled 5B6 TCR transgenic T cells were treated i.v. with $\mathrm{OVA}_{323-339}$-PSB or PLP ${ }_{139-151}$-PSB and primed with PLP $_{139-151}$ plus CFA 5 d later. Data shown are representative of three independent experiments. 

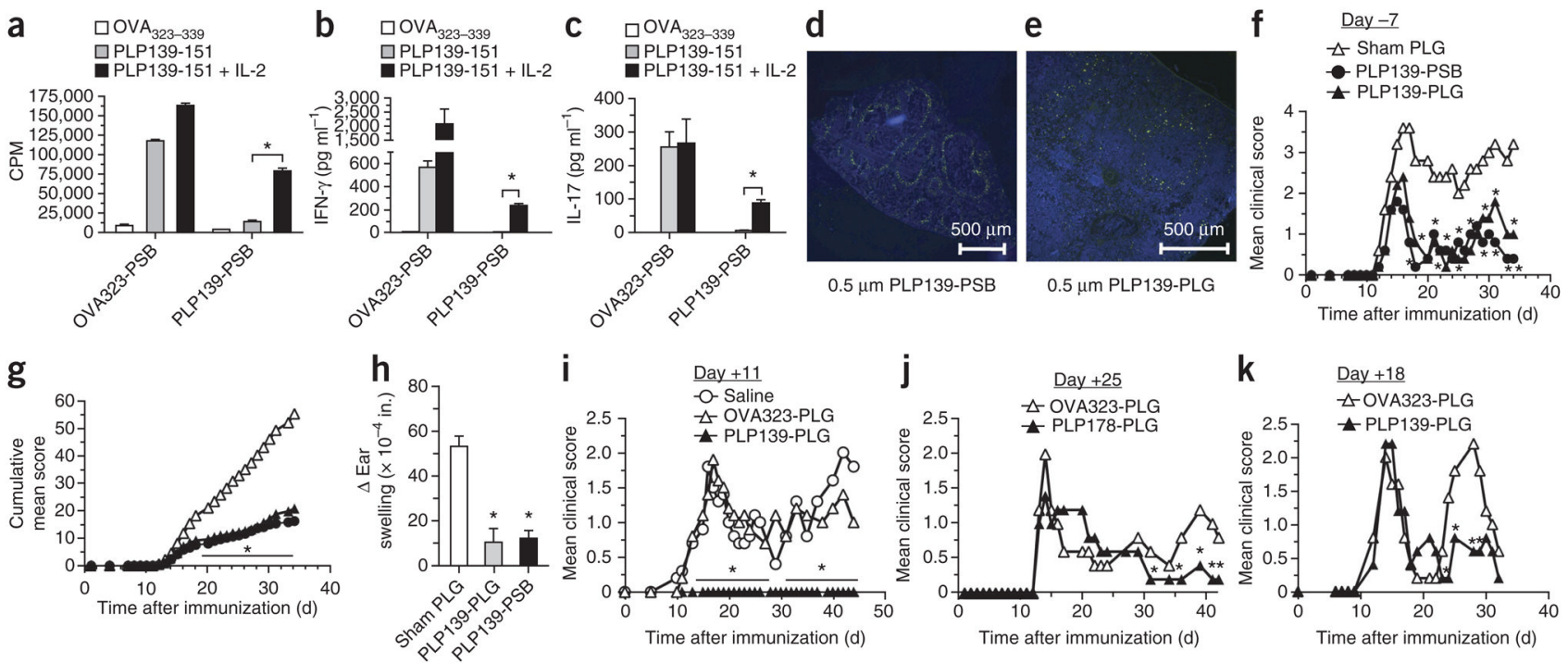

Figure 6.

Short-term tolerance induced by i.v. treatment with Ag-PSB is caused primarily by anergy induction. (a-c) SJL/J mice were treated i.v. with OVA $323-339$-PSB (OVA323-PSB) or

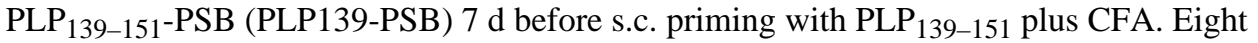
days after priming, the proliferation of spleen and lymph nodes in response to stimulation with the priming antigen ( $\left.\mathrm{PLP}_{139-151}\right)$ or a control antigen $\left(\mathrm{OVA}_{323-339}\right)$ in the presence of absence of $200 \mathrm{U} \mathrm{ml}-1$ of exogenous IL-2 was measured (a). Supernatants were collected for measurements of secreted IFN- $\gamma(\mathbf{b})$ and IL-17A (c). Results are representative of 3-4 separate experiments. (d,e) SJL/J mice were treated with 500-nm FITC-PSB (d) or 500-nm biodegradable FITC-PLG microparticles (e) coupled with PLP ${ }_{139-151}$. Twelve hours later, frozen spleen sections were prepared from a subset of mice, and these sections were counterstained with DAPI (blue). (f-i) On day -7 (f-h) or day +11 (i) relative to PLP PIS-151 $_{139}$ plus CFA priming, mice were injected with 500-nm PLP $139-151-\mathrm{PSB}$ or $\mathrm{PLP}_{139-151}-\mathrm{PLG}$ (PLP139-PLG) microparticles and monitored for development of clinical disease by assessing mean clinical score (f,i) and cumulative mean clinical score (g) over time. (h) At the conclusion of the experiment, the mice from $\mathbf{f}$ were ear challenged with PLP $\mathrm{P}_{139-151}$, and DTH responses were determined. (j,k) SJL/J mice were tolerized with 500-nm PLP $178-191^{-}$ PLG (PLP178-PLG) or OVA 323-339-PLG (OVA323-PLG) microparticles on day +25 after PLP $_{139-151}$ plus CFA priming (j) or with 500-nm PLP ${ }_{139-151}$-PLG or OVA $323-339-\mathrm{PLG}$ microparticles on day +18 after PLP $_{178-191}$ plus CFA priming (k) and monitored for clinical disease. Error bars, s.e.m. $* P \leq 0.01$ (ANOVA) for the differences in proliferation, mean clinical scores and DTH responses compared to groups tolerized to sham PLG particles. Data shown are representative of 2-3 separate experiments of 5-7 mice per group. 